\title{
Solid-State Fermentation of Carrot Pomace for the Production of Inulinase by Penicillium oxalicum BGPUP-4
}

\author{
Ram Sarup Singh ${ }^{1 *}$, \\ Kanika Chauhan', Jagroop \\ Singh', Ashok Pandey ${ }^{2}$ \\ and Christian Larroche ${ }^{3}$ \\ 'Carbohydrate and Protein \\ Biotechnology Laboratory, \\ Department of Biotechnology, \\ Punjabi University, 147002 Patiala, \\ Punjab, India \\ ${ }^{2}$ CSIR-Indian Institute of Toxicology \\ Research, 31 Marg, 226001 Lucknow, \\ India \\ ${ }^{3}$ University Clermont Auvergne, \\ Institute Pascal, UMR, CNRS 6602, and \\ LabEx IMobS3, 4 avenue Blaise Pascal, \\ TSA 60026, CS 60026, FR- \\ -63178, Aubiere cedex, France
}

Received: July 5, 2017 Accepted: November 2, 2017

\section{${ }^{*}$ Corresponding author: \\ Phone: +911753046262; \\ Fax: +911752283073. \\ E-mail: rssingh11@lycos.com, rssbt@pbi.ac.in}

ORCID IDs: 0000-0003-1286-6373 (Singh), 0000-0003-4439-549X (Chauhan), 0000-0001-9203-6825 (Singh), 0000-0003-1626-3529 (Pandey), 0000-0001-7348-9191 (Larroche)

Paper was presented at the 7th International Forum on Industrial Bioprocessing - IFIBiop 2017, May 21-24 2017, Wuxi, PR China

\section{SUMMARY}

Inulinases are an important class of industrial enzymes which are used for the production of high-fructose syrup and fructooligosaccharides. Inulin, a polyfructan, is generally employed for the production of inulinase, which is a very expensive substrate. A number of agroindustrial residues have been used for cost-effective production of inulinases. In the present study, carrot pomace was selected as a substrate for the production of inulinase by Penicillium oxalicum BGPUP-4 in solid-state fermentation. Carrot pomace is one of the good substrates for bioprocesses, because it is rich in soluble and insoluble carbohydrates. A central composite rotatable design (CCRD) used in response surface methodology was employed for the optimal production of inulinase from carrot pomace. Using CCRD, 15 runs were practiced to optimize the range of three independent variables: moisture content (70-90\%), incubation time (4-6 days) and pH (5.0-7.0) for inulinase production. Carrot pomace supplemented with $0.5 \%$ inulin as an inducer, $0.2 \% \mathrm{NH}_{4} \mathrm{H}_{2} \mathrm{PO}_{4^{\prime}} 0.2 \% \mathrm{NaNO}_{3^{\prime}} 0.2 \% \mathrm{KH}_{2} \mathrm{PO}_{4^{\prime}} 0.05 \% \mathrm{MgSO}_{4} \cdot 7 \mathrm{H}_{2} \mathrm{O}$ and 0.001 $\% \mathrm{FeSO}_{4} \cdot 7 \mathrm{H}_{2} \mathrm{O}$ was used for the production of inulinase in solid-state fermentation at $30{ }^{\circ} \mathrm{C}$. Inulinase production (322.10 IU per g of dry substrate) was obtained under the optimized conditions, i.e. moisture content of $90 \%$, incubation time 4 days and $\mathrm{pH}=7.0$. The corresponding inulinase/invertase (I/S) ratio (3.38) was also high, which indicates the inulolytic nature of the enzyme. Multiple correlation coefficients $\mathrm{R}$ for inulinase production and $\mathrm{I} / \mathrm{S}$ ratio were 0.9995 and 0.9947 , respectively. The $R$ value very close to one indicates an excellent correlation between experimental and predicted results.

Key words: inulinase, carrot pomace, Penicillium oxalicum, solid-state fermentation, response surface methodology

\section{INTRODUCTION}

Inulinases are important industrial hydrolysing enzymes which belong to glycoside hydrolase (GH) family 32. They act on $\beta-2,1$ linkages of inulin to produce high-fructose syrup (HFS) or fructooligosaccharides (FOSs). On the basis of their degrading action on inulin, inulinases are classified as exoinulinases or endoinulinases. Exoinulinase (EC 3.2.1.80, $\beta$-2-1-D-fructan fructohydrolase) acts sequentially on inulin to liberate fructose units from its non-reducing end, while endoinulinase (EC 3.2.1.7, $\beta$-2-1-D-fructan fructanohydrolase) randomly hydrolyses internal linkages of inulin to release FOSs. The two major applications of inulinases are the production of HFS (1-3) and FOSs $(4,5)$. Microbial sources such as filamentous fungi, yeast and bacteria are considered as a preferred choice for inulinase production over plant and animal sources $(6,7)$. This may be ascribed to their easy cultivation and high enzyme yield. In recent years, interest in exploring fungal inulinase sources has increased tremendously (8). This can be attributed to their advantageous features like growth on low-value substrates and synergism between exo- and endoinulinase for end-product formation. Amongst them, Aspergillus sp. and Penicillium sp. are reported as good inulinase producers (6). 
Fermentation technique, type of microorganism and medium constituents are some key factors which play a vital role in enzyme production. Conventionally, inulinases are produced by submerged fermentation (6,7), however, solid-state fermentation (SSF) has also been used for their production $(6,7)$. Fungal sources, due to their xerophytic characteristics, can easily flourish at low moisture level and they are preferentially used to carry out SSF of solid substrates. Wheat bran, soybean bran, sugarcane bagasse, press mud, artichoke, banana leaves, chicory root, garlic waste, orange rind, etc. are some common solid substrates used for inulinase production (6). The use of agroindustrial wastes like apple pomace, carrot pomace, orange rinds, etc. as substrates has gained interest of researchers, due to their easy availability and low cost. Amongst them, carrot pomace has been determined to possess various potential applications. It is an important byproduct of carrot juice extraction unit. The pomace is quite perishable as it contains $88 \%$ of moisture and is a rich source of carotenoids, uronic acids, dietary fibre and neutral sugars (9). Previously, it was mostly utilized as a cattle feed and manure. Due to the increasing trend towards efficient utilization of agroindustrial residues, carrot pomace has also been used for the supplementation of several bakery and functional products (9). Recently, it has also been used for the bioethanol production (10). In the present investigation, production of inulinase from carrot pomace by Penicillium oxalicum BGPUP-4 under SSF was carried out using response surface methodology. This is the first report on inulinase production from carrot pomace by SSF.

\section{MATERIALS AND METHODS}

\section{Fungal culture}

Penicillium oxalicum BGPUP-4, an isolate from our laboratory (Punjabi University, Patiala, India), was used for the production of inulinase. The fungal culture was maintained on potato dextrose agar (PDA; HiMedia Laboratories Pvt. Ltd., Mumbai, India) slants as described previously (11).

\section{Inoculum preparation}

Inoculum was prepared by growing a stock culture of $P$. oxalicum BGPUP-4 in Erlenmeyer flasks containing PDA at 30 ${ }^{\circ} \mathrm{C}$ for 5 days. After incubation, fungal spores were harvested and suspended in sterile distilled water containing $0.01 \%$ (by volume) Tween 80 (HiMedia Laboratories Pvt. Ltd). The spores were dislodged from the hyphae with the aid of a sterile glass rod. Thereafter, the spore suspension was filtered through a sterile absorbent cotton wool plug to remove any remaining traces of hyphal fragments. The number of spores was counted using a haemocytometer (model BR718920; Sigma-Aldrich, St. Louis, MO, USA) and microscope (model CH20i; Olympus Opta Systems Pvt. Ltd, New Delhi, India). The number of spores in the inoculum was adjusted to $10^{4} \mathrm{spore} / \mathrm{mL}$ with presterilized distilled water, under aseptic conditions.

\section{Preparation of substrate}

Fresh carrots were procured from the local market, Patiala, India. After thorough washing, they were crushed properly in a juice extraction machine (Philips India Ltd., Gurgaon, India) to obtain juice. Carrot residue obtained after the extraction was pressed and dried in an oven (Narang Scientific Works Pvt. Ltd, New Delhi, India) at $50{ }^{\circ} \mathrm{C}$, until it dehydrated completely. The dried carrot pomace was ground using mortar and pestle to uniform powder and passed through a $150-\mu \mathrm{m}$ sieve.

\section{Solid-state fermentation}

Solid-state fermentations (SSF) were carried out in Erlenmeyer flasks $(250 \mathrm{~mL})$ containing $10 \mathrm{~g}$ of carrot pomace moistened with distilled water containing (in $\%$, mass per volume): inulin 0.5, $\mathrm{NaNO}_{3} 0.2, \mathrm{KH}_{2} \mathrm{PO}_{4} 0.2, \mathrm{KCl} 0.1, \mathrm{MgSO}_{4} \cdot 7 \mathrm{H}_{2} \mathrm{O} 0.05$, FeSO $\cdot 7 \mathrm{H}_{2} \mathrm{O} 0.001$ and $\mathrm{NH}_{4} \mathrm{H}_{2} \mathrm{PO}_{4} 0.2$ (all from HiMedia Laboratories Pvt. Ltd.). Three variables optimized for inulinase production using statistical experimental model are A: moisture content (70-90 \%), B: incubation time (4-6 days) and C: pH (57 ), while the other above-mentioned medium constituents were kept constant during the progression of the study. The Erlenmeyer flasks were sealed with hydrophobic cotton and autoclaved at $121{ }^{\circ} \mathrm{C}$ for $30 \mathrm{~min}$. Preliminary studies showed no changes in the moisture content of the substrate after autoclaving. After cooling, the flasks were inoculated with previously prepared $2 \mathrm{~mL}$ of spore suspension $\left(10^{4} \mathrm{spore} / \mathrm{mL}\right)$ and mixed uniformly with a sterile glass rod, under aseptic conditions. Subsequently, flasks were incubated in an environmental chamber (model CHM-10 Plus; REMI Lab World, Mumbai, India) with temperature and humidity control.

\section{Statistical optimization of inulinase production by $P$. oxalicum BGPUP-4 using carrot pomace as substrate}

Optimization of fermentation conditions is an important factor in developing feasible bioprocess to obtain desirable product. Optimal processing conditions can be constituted using an efficacious statistical experimental model. Central composite rotatable design (CCRD) used in response surface methodology (RSM) is a collection of several statistical models and has been employed to study the influence of three different variables and their combined interactions on inulinase production by $P$. oxalicum BGPUP-4. Statistical analysis was carried out using Design expert v. 7.0.0 software package (Stat-Ease Inc., Minniapolis, MN, USA). The variables were optimized using $2^{3}$ factorial design. The five coded levels used to study three independent variables were $-1.414,-1,0,1$ and 1.414 (Table 1). CCRD produced a total of 15 combinations which comprised four factorial and six axial points, and five replicates at the centre point. The experimental runs 1, 3-5 and 14 at the centre point were used to find experimental inaccuracy and duplicability of the results. All the experiments were carried out in triplicates. To substantiate the model's accuracy, validation of experiments was performed to equate predicted and experimental results. 
Table 1. Coded and actual levels of independent variables used in experimental design

\begin{tabular}{ccccccc} 
Independent & & \multicolumn{5}{c}{ Actual level of coded factors } \\
\cline { 3 - 7 } variable & Code & -1.414 & -1 & 0 & 1 & 1.414 \\
$w($ moisture $) / \%$ & $\mathrm{~A}$ & 65.86 & 70 & 80 & 90 & 94.14 \\
$t($ incubation)/day & $\mathrm{B}$ & 3.59 & 4 & 5 & 6 & 6.41 \\
$\mathrm{pH}$ & $\mathrm{C}$ & 4.59 & 5 & 6 & 7 & 7.41 \\
\hline
\end{tabular}

Inulinase production and I/S ratio were the two responses on which the influence of three chosen independent variables was anticipated. A multiple regression analysis of experimental data obtained from an empirical model was accomplished using least square method, to fit into the following second-order polynomial equation:

$$
Y=\beta_{0}+\sum \beta_{i} X_{i}+\sum \beta_{i i} X_{i}^{2}+\sum \beta_{i j} X_{i} X_{j}
$$

where $Y$ is measured response, $\beta_{0}$ is the intercept term, $\beta_{i}$ is linear coefficient, $\beta_{\mathrm{ii}}$ is quadratic coefficient, $\beta_{\mathrm{ij}}$ is an interaction coefficient and $X_{i}$ and $X_{i}$ represent coded independent variables. The statistical implication of the model was revealed through analysis of variance (ANOVA) for polynomial model with $95 \%$ confidence level. Student's $t$-test and Fisher's F-test were also applied to ascertain statistical significance of regression coefficients and to evaluate significance of second-order model equation and terms. Besides, the excellence of the polynomial model can be exhibited in terms of coefficient of determination $\left(R^{2}\right)$, adjusted $R^{2}$ and adequate precision. The value of $R^{2}$ is important to explain the variability in the observed responses with respect to experimental factors and interactions between them. Moreover, 2D contour plots were also analysed to study interaction between each variable and its corresponding effect.

\section{Extraction of inulinase}

After successful fermentations, the extracellular enzyme was extracted by adding $100 \mathrm{~mL}$ of sodium acetate buffer ( 0.1 $\mathrm{M}, \mathrm{pH}=5.0$; HiMedia Laboratories Pvt. Ltd) to the fermented substrate in Erlenmeyer flasks. The content of each flask was kept under agitation (150 rpm) on a rotary incubator shaker (model CIS-24 BL; REMI Lab World) for $2 \mathrm{~h}$ at $30^{\circ} \mathrm{C}$ for enzyme extraction. Thereafter, the extract was filtered through Whatman No. 1 filter paper and centrifuged at $3000 \times g$ (model REMI CPR-30 Plus; REMI Elektrotechnik Ltd., Mumbai, India) for $10 \mathrm{~min}$ at $4{ }^{\circ} \mathrm{C}$. Supernatant was collected as crude inulinase produced by SSF. It was then analysed for inulinase and invertase activities. Inulinase/invertase activity ratio (I/S) was also calculated.

\section{Analytical techniques}

\section{Inulinase assay}

Crude enzyme (100 $\mu \mathrm{L})$ obtained after extraction was mixed with $900 \mu \mathrm{L}$ of substrate solution ( $2 \%$ inulin; HiMedia Laboratories Pvt. Ltd) in $0.1 \mathrm{M}$ sodium acetate buffer, $\mathrm{pH}=5.0$; HiMedia Laboratories Pvt. Ltd). Reaction mixture was incubated at $55^{\circ} \mathrm{C}$ for $10 \mathrm{~min}$. Then, the reaction was stopped by heating the reaction mixture in boiling water bath (model NSW-133; Narang Scientific Works Pvt. Ltd) for 10 min. After that, reducing sugar content in the mixture was determined by 3,5-dinitrosalicylic acid (DNSA) method (12). One unit of inulinase is defined as the amount of enzyme that produces one $\mu \mathrm{mol}$ of fructose per minute under assay conditions.

\section{Invertase assay}

The reaction mixture $(1.0 \mathrm{~mL})$ comprising crude enzyme extract $(100 \mu \mathrm{L})$ and substrate solution (2 \% sucrose; HiMedia Laboratories Pvt. Ltd) in $0.1 \mathrm{M}$ sodium acetate buffer ( $\mathrm{pH}=5.0$; HiMedia Laboratories Pvt. Ltd) was incubated at $55^{\circ} \mathrm{C}$ for 10 min. After incubation, the reaction was terminated by degrading the enzyme in the reaction mixture at $100{ }^{\circ} \mathrm{C}$ for 10 min. The resultant hydrolysate was analysed for reducing sugars by DNSA method (12). One invertase unit is defined as the amount of enzyme that produces one $\mu \mathrm{mol}$ of reducing sugars per minute under assay conditions.

I/S ratio

Activity of the enzyme on inulin or sucrose as a substrate is crucial for its characterization, because of the participation of its single active site in both fructan and sucrose hydrolysis. Generally, the ratio of activity on inulin versus sucrose (I/S) is used to determine catalytic nature of the enzyme. High I/S ratio indicates inulolytic nature of the enzyme. I/S ratio was calculated from inulinase/invertase activity.

\section{RESULTS AND DISCUSSION}

\section{Statistical optimization of significant variables using CCRD and ANOVA}

Moisture content, incubation time and $\mathrm{pH}$ were considered as significant variables for statistical optimization of inulinase production from carrot pomace in SSF. The experimental design matrix was calculated using CCRD. Linear, 2F1, quadratic and cubic models were analysed to find the regression equation of the experimental data. The experimental design and the results obtained after statistical optimization of the two responses, i.e. inulinase production and $\mathrm{I} / \mathrm{S}$ ratio are shown in Table 2. A suitable model, i.e. quadratic model chosen because of high $\mathrm{F}$ value, was assessed on the basis of sequential sum of squares and analysis of variance (ANOVA) results. The $F$ value is the ratio of the mean squares of the regression and the mean squares of the error, which specifies the significance of each factor in the model (13). The higher $F$ values of 1173.87 and 104.75 for inulinase production and I/S ratio, respectively, justify the significance of the model. The experimental results corresponded with a second order polynomial equation. The values of regression coefficients were calculated and the fitted equations (in terms of coded values) for predicting inulinase production and I/S ratio, regardless of the coefficient significance were as given below: 
Table 2. Central composite rotatable design matrix for inulinase production on dry mass basis and inulinase/invertase ratio (I/S) obtained from solid-state fermentation of carrot pomace by Penicillium oxalicum BGPUP-4

\begin{tabular}{|c|c|c|c|c|c|c|c|}
\hline \multirow{3}{*}{ Run } & \multicolumn{3}{|c|}{ Factor* } & \multicolumn{2}{|c|}{ Experimental results } & \multicolumn{2}{|c|}{ Predicted results } \\
\hline & \multirow{2}{*}{ A } & \multirow{2}{*}{ B } & \multirow{2}{*}{ C } & Inulinase production & \multirow{2}{*}{$\mathrm{I} / \mathrm{S}$} & Inulinase production & \multirow{2}{*}{$\mathrm{I} / \mathrm{S}$} \\
\hline & & & & $\mathrm{IU} / \mathrm{g}$ & & $\mathrm{IU} / \mathrm{g}$ & \\
\hline 1 & 80.00 & 5.0 & 6.0 & 275.00 & 4.09 & 274.55 & 4.11 \\
\hline 2 & 80.00 & 3.6 & 6.0 & 309.80 & 3.63 & 310.25 & 3.39 \\
\hline 3 & 80.00 & 5.0 & 6.0 & 274.00 & 4.04 & 274.55 & 4.11 \\
\hline 4 & 80.00 & 5.0 & 6.0 & 275.30 & 3.94 & 274.55 & 4.11 \\
\hline 5 & 80.00 & 5.0 & 6.0 & 275.20 & 4.11 & 274.55 & 4.11 \\
\hline 6 & 90.00 & 4.0 & 7.0 & 322.10 & 3.38 & 321.61 & 3.33 \\
\hline 7 & 80.00 & 5.0 & 7.4 & 280.60 & 3.68 & 281.18 & 3.54 \\
\hline 8 & 80.00 & 5.0 & 4.6 & 279.50 & 3.83 & 280.08 & 3.42 \\
\hline 9 & 70.00 & 6.0 & 7.0 & 291.80 & 3.94 & 291.13 & 4.35 \\
\hline 10 & 90.00 & 6.0 & 5.0 & 272.70 & 3.74 & 272.03 & 4.27 \\
\hline 11 & 70.00 & 4.0 & 5.0 & 286.20 & 3.03 & 285.71 & 3.24 \\
\hline 12 & 65.86 & 5.0 & 6.0 & 281.70 & 3.92 & 282.28 & 4.11 \\
\hline 13 & 80.00 & 6.4 & 6.0 & 278.30 & 5.63 & 279.01 & 4.84 \\
\hline 14 & 80.00 & 5.0 & 6.0 & 274.40 & 4.08 & 274.55 & 4.11 \\
\hline 15 & 94.14 & 5.0 & 6.0 & 286.20 & 4.11 & 286.78 & 4.11 \\
\hline
\end{tabular}

*Symbols A, B and C are the same as in Table 1

Inulinase production $=+274.81+1.59 \cdot A-11.14 \cdot B+0.035 \cdot C-$ $-12.21 \cdot A \cdot B+1.21 \cdot A \cdot C-4.11 \cdot B \cdot C+4.54 \cdot A^{2}+9.59 \cdot B^{2}+2.84 \cdot C^{2} \quad / 2 /$

$\mathrm{I} / \mathrm{S}=+4.08-0.19 \cdot \mathrm{A}-0.046 \cdot \mathrm{B}-0.088 \cdot \mathrm{C}-0.22 \cdot \mathrm{A} \cdot \mathrm{B}-0.30 \cdot \mathrm{A} \cdot \mathrm{C}-$ $-0.24 \cdot B \cdot C-0.21 \cdot A^{2}-0.25 \cdot B^{2}-0.18 \cdot C^{2}$

where $\mathrm{A}$ is moisture content, $\mathrm{B}$ is incubation time, and $\mathrm{C}$ is $\mathrm{pH}$.

The statistical relevance of Eqs. 2 and 3 for response surface quadratic model was established by ANOVA. Statistical data given in Table 3 indicate that the model is highly significant. Fisher's F-test and student's t-test were used to determine significance of the coefficients of the independent variables. Higher $\mathrm{F}$ value and smaller probability $>\mathrm{F}$ value confirm the significance of the corresponding coefficient term. The probability $>F$ value less than 0.05 suggests the significance of each coefficient. It is necessary to define the pattern of interaction between the two coefficients (Table 4). The smaller the probability $>F$ value, the more significant the corresponding coefficient (14-17). $A, B, C, A B, A C, B C, A^{2}, B^{2}$ and $C^{2}$ are the significant model terms for inulinase production. Amongst them, $B, A B, B C, A^{2}, B^{2}$ and $C^{2}$ were extremely significant ( $p>0.0001$ ). For $\mathrm{I} / \mathrm{S}$ ratio, $A, B, C, A B, A C, B C, A^{2}, B^{2}$ and $C^{2}$ were also significant, but $A^{2}, B^{2}$ and $C^{2}$ were the most significant terms $(p>0.0001)$. The degree of freedom for pure error for both, inulinase production and I/S ratio, was 4, which once more manifests the authenticity of the models. Probability $>F$ and $F$ values of the lack-of-fit for inulinase production were 0.7075 and 0.16 , while for I/S ratio they were 0.2441 and 1.86 , respectively. This implies that the lack-of-fit is not significant compared to the pure error, which justifies the fitness of the quadratic model for the present study.

The goodness of fit of the model is shown in Table 5. Multiple correlation coefficient $\mathrm{R}$ is a scalar, which is used to define the correlation between the actual and predicted values of the variable. The higher $\mathrm{R}$ values of 0.9995 and 0.9947 for inulinase production and I/S ratio, respectively, showed good agreement between actual and predicted values. The adjusted $R^{2}$ and predicted $R^{2}$ were 0.9987 and 0.9973 for inulinase production, and 0.9852 and 0.8134 for I/S ratio, respectively. A minute difference between the adjusted $R^{2}$ and predicted $\mathrm{R}^{2}$ showed reasonable agreement between the two values. Adequate precision measures the signal to noise ratio. A ratio greater than 4 is advisable, therefore, the ratio of 118.71 and 32.61 for inulinase production and I/S ratio, respectively, indicates an adequate signal for the present model and suggests that the model can be used to navigate the design space.

The quadratic models in Eqs. 2 and 3 have nine terms comprising three linear terms, three quadratic terms and three two-factorial interactions. Out of these terms, the insignificant terms ( $p>0.05$ ) were found only in Eq. 2, which were neglected, resulting in the following equation:

Inulinase production $=+274.81+1.59 \cdot A-11.14 \cdot B-12.21 \cdot A \cdot B+$ $+1.21 \cdot A \cdot C-4.11 \cdot B \cdot C+4.54 \cdot A^{2}+9.59 \cdot B^{2}+2.84 \cdot C^{2}$ 
Table 3. Analysis of variance (ANOVA) for the experimental results obtained from central composite rotatable design

\begin{tabular}{|c|c|c|c|c|c|c|}
\hline \multirow[t]{2}{*}{ Source* } & \multicolumn{3}{|c|}{ Inulinase production/(IU/g) } & \multicolumn{3}{|c|}{$\mathrm{I} / \mathrm{S}$} \\
\hline & Sum of squares & df & Probability $>$ F & Sum of squares & df & Probability $>F$ \\
\hline Model & 2744.12 & 9 & $<0.0001$ & 1.51 & 9 & $<0.0001$ \\
\hline$A$ & 10.13 & 1 & 0.0015 & 0.15 & 1 & 0.0002 \\
\hline B & 96.13 & 1 & $<0.0001$ & $8.450 \cdot 10^{-3}$ & 1 & 0.0703 \\
\hline$A B$ & 298.40 & 1 & $<0.0001$ & 0.093 & 1 & 0.0006 \\
\hline$A C$ & 3.45 & 1 & 0.0148 & 0.18 & 1 & 0.0001 \\
\hline $\mathrm{BC}$ & 33.77 & 1 & $<0.0001$ & 0.11 & 1 & 0.0004 \\
\hline$A^{2}$ & 158.80 & 1 & $<0.0001$ & 0.33 & 1 & $<0.0001$ \\
\hline $\mathrm{B}^{2}$ & 709.03 & 1 & $<0.0001$ & 0.49 & 1 & $<0.0001$ \\
\hline$C^{2}$ & 62.09 & 1 & $<0.0001$ & 0.24 & 1 & $<0.0001$ \\
\hline Residual & 1.30 & 5 & & $8.031 \cdot 10^{-3}$ & 5 & \\
\hline Lack-of-fit & 0.051 & 1 & 0.7075 & $2.551 \cdot 10^{-3}$ & 1 & 0.2441 \\
\hline Pure error & 1.25 & 4 & & $5.480 \cdot 10^{-3}$ & 4 & \\
\hline Cor total & 2745.42 & 14 & & 1.52 & 14 & \\
\hline
\end{tabular}

*Symbols A, B and C are the same as in Table 1, $1 / \mathrm{S}=$ =inulinase/inverstase, Cor total=corrected total sum of squares

Table 4. Regression coefficients and significance of the quadratic model for inulinase production on dry mass basis and ratio of inulinase and invertase $(I / S)$

\begin{tabular}{|c|c|c|c|c|c|c|}
\hline \multirow[t]{2}{*}{ Source* } & \multicolumn{3}{|c|}{ Inulinase production/(IU/g) } & \multicolumn{3}{|c|}{ I/S } \\
\hline & $\begin{array}{l}\text { Coefficient } \\
\text { estimate }\end{array}$ & Standard error & F-value & $\begin{array}{l}\text { Coefficient } \\
\text { estimate }\end{array}$ & Standard error & F-value \\
\hline Intercept & 274.81 & 0.22 & 1173.87 & 4.08 & 0.017 & 104.75 \\
\hline A & 1.59 & 0.25 & 38.98 & -0.19 & 0.020 & 90.77 \\
\hline B & -11.14 & 0.25 & 1910.08 & -0.046 & 0.020 & 5.26 \\
\hline C & 0.035 & 0.25 & 0.019 & -0.088 & 0.020 & 19.45 \\
\hline$A B$ & -12.21 & 0.36 & 1148.82 & -0.22 & 0.028 & 58.03 \\
\hline AC & 1.31 & 0.36 & 13.28 & -0.30 & 0.028 & 114.66 \\
\hline BC & -4.11 & 0.36 & 130.01 & -0.24 & 0.028 & 70.78 \\
\hline$A^{2}$ & 4.54 & 0.18 & 611.36 & -0.21 & 0.014 & 208.26 \\
\hline$B^{2}$ & 9.59 & 0.18 & 2729.76 & -0.25 & 0.014 & 301.94 \\
\hline$C^{2}$ & 2.84 & 0.18 & 239.05 & -0.18 & 0.014 & 148.33 \\
\hline
\end{tabular}

*Symbols A, B and C are the same as in Table 1

Table 5. Goodness-of-fit

\begin{tabular}{|c|c|c|c|c|c|}
\hline \multirow[t]{3}{*}{ Source } & \multicolumn{2}{|c|}{ Value } & \multirow[t]{3}{*}{ Source } & \multicolumn{2}{|l|}{ Value } \\
\hline & Inulinase production & \multirow{2}{*}{$\mathrm{I} / \mathrm{S}$} & & Inulinase production & \multirow{2}{*}{$\mathrm{I} / \mathrm{S}$} \\
\hline & $\mathrm{IU} / \mathrm{g}$ & & & $\mathrm{IU} / \mathrm{g}$ & \\
\hline S.D. & 0.51 & 0.04 & $\mathrm{R}^{2}$ & 0.99 & 0.99 \\
\hline Mean & 283.85 & 3.74 & Adjusted $\mathrm{R}^{2}$ & 0.99 & 0.98 \\
\hline $\mathrm{CV} / \%$ & 0.18 & 1.07 & Predicted $\mathrm{R}^{2}$ & 0.99 & 0.81 \\
\hline Press & 7.36 & 0.28 & Adeq. precision & 118.71 & 32.61 \\
\hline
\end{tabular}

$\mathrm{I} / \mathrm{S}=$ inulinase/invertase, S.D.=standard deviation, $\mathrm{CV}=$ coefficient of variance 


\section{Effect of independent variables and their interactions on inulinase production}

The effect of three independent variables on inulinase production and I/S ratio was studied. Fig. 1 and Fig. 2 show response surface contour plots of the two responses. These plots demonstrate pairwise combination of factors, while keeping the third one at its optimal level. Moreover, they also highlight the role of each factor. The effects of different combinations of the three variables were interpreted. It is apparent from the plots that moisture content has a profound effect on inulinase production, which increases with the increase in moisture content. Maximum inulinase production was obtained at moisture level of $90 \%$, while at its further increase, decrease in inulinase production was observed (Figs. 1a and

a)

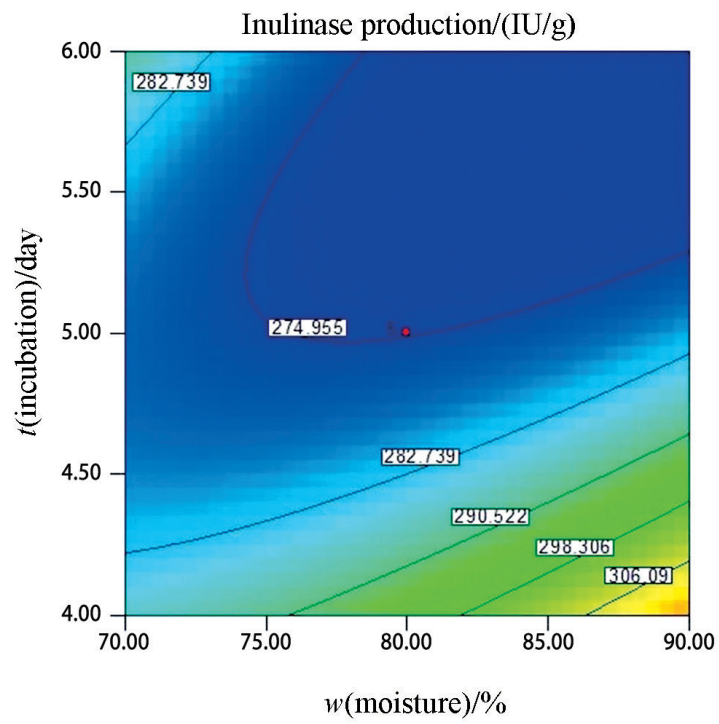

1b). Similar response of moisture content on inulinase production by Pichia guilliermondii in SSF has also been reported (18). Nuñez-Gaona et al. (19) also reported that only a certain level of moisture is enough to accelerate nutrient absorption, normal metabolic function and fungal conidial production. Requirement of moisture content can vary from species to species. Generally, minimum of $20 \%$ of moisture level is essential for fungal growth, while very high moisture content may retard conidial induction (19). The increase in $\mathrm{pH}$ up to 7.0 has also shown a significant influence on inulinase production. However, further increase in $\mathrm{pH}$ decreased the inulinase production (Figs. $1 \mathrm{~b}$ and $1 \mathrm{c}$ ). A small change in ion balance can instantly affect fungal growth by creating alterations in its cell surface, which concatenates enzyme production or

b)

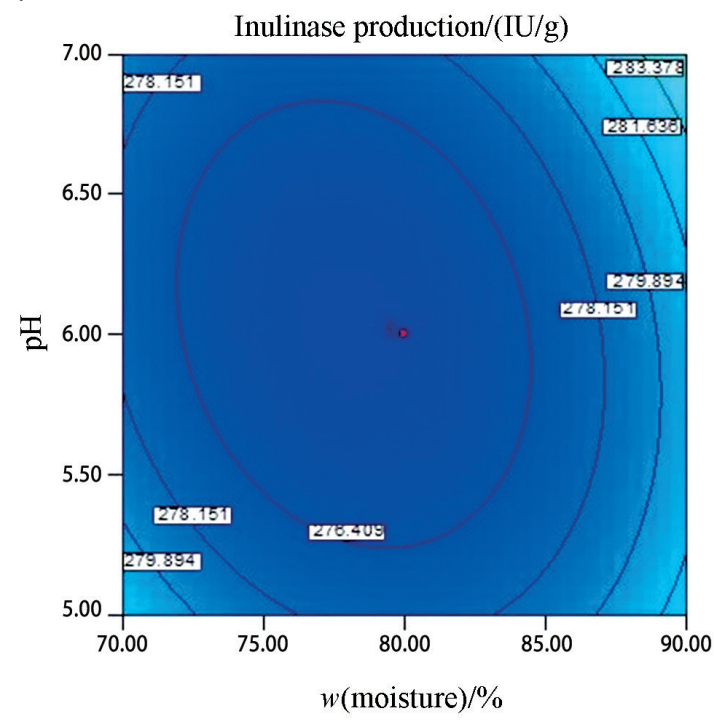

c)

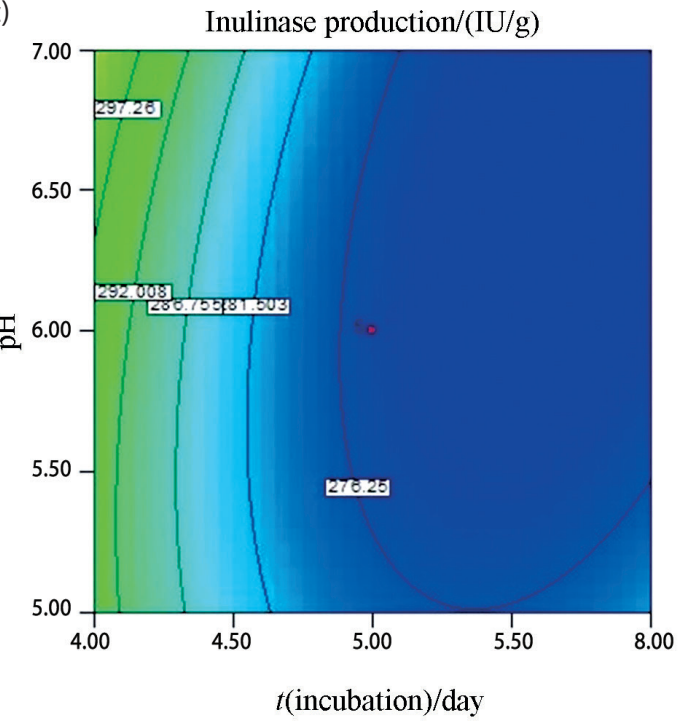

Fig. 1. Response surface contour plots of: a) moisture content and incubation time, b) moisture content and $\mathrm{pH}$, and c) incubation time and pH for inulinase production by Penicillium oxalicum BGPUP-4 
a)

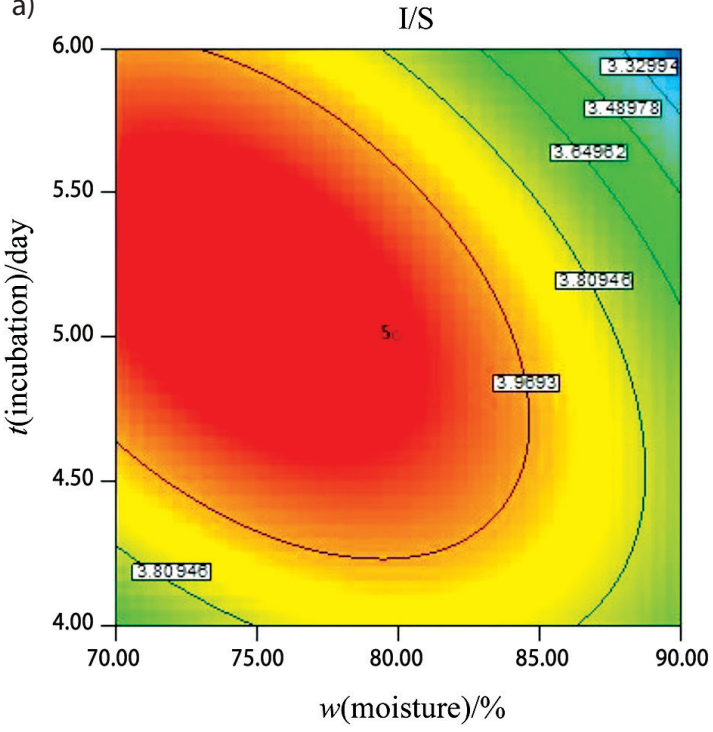

b)

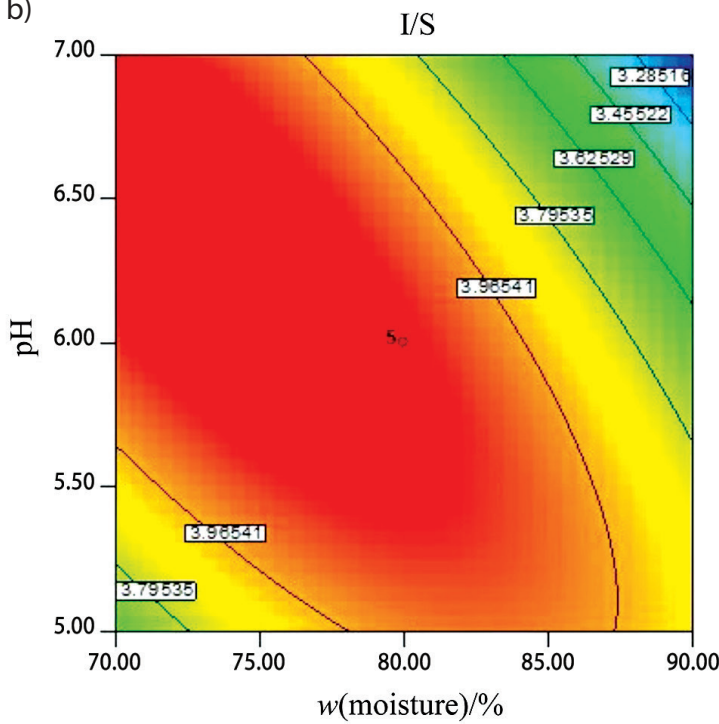

C)

$\mathrm{I} / \mathrm{S}$

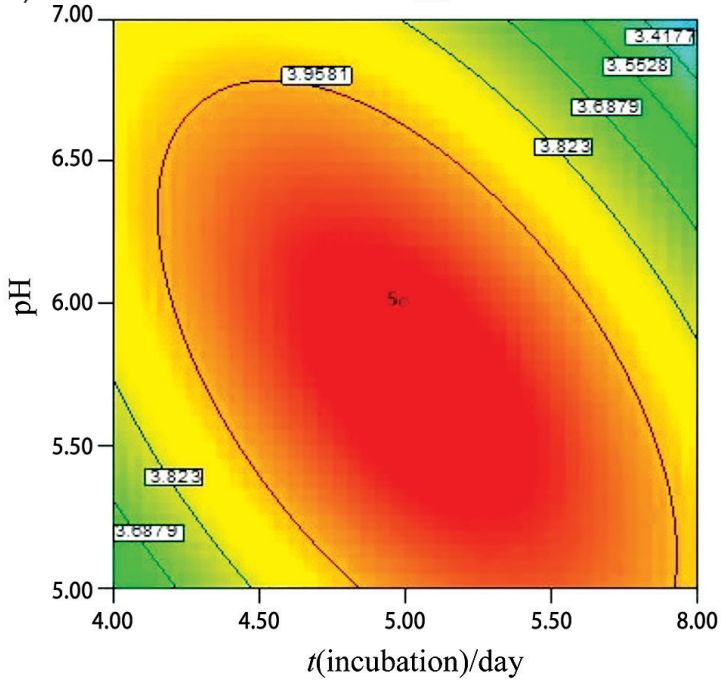

Fig. 2. Response surface contour plots of: a) moisture content and incubation time, b) moisture content and pH, and c) incubation time and pH for inulinase and invertase ratio (I/S) produced by Penicillium oxalicum BGPUP-4

reduction. Our findings are in abidance with the results obtained with Pichia guilliermondii (18), A. niger (20) and Kluyveromyces marxianus (21), where maximum inulinase production was reported at $\mathrm{pH}$ close to 7.0. Incubation time is also a pivotal factor for enzyme production. It has been reported that incubation period influences $\mathrm{pH}$ of the medium. With extended incubation period, $\mathrm{CO}_{2}$ or acidic metabolites released by aerobic microbial cells accumulate in the medium, which makes it slightly acidified (22). P. oxalicum BGPUP-4 produced maximum inulinase after 4 days of incubation. After 4 days of fermentation, a slight decrease in inulinase production was observed, which may be attributed to secretion of proteases into the medium that denature the enzyme by hydrolysing peptide bonds between amino acids. Additionally, change in medium optimal conditions with incubation time may also have contributed to inulinase inhibition. Our results corroborate the findings on inulinase production by Bacillus safensis (23) and Penicillium funiculosum (24).

Many microbial sources have been reported to possess remarkable invertase activity along with inulinase activity. This mainly occurs due to the specificity of single active site of an enzyme for both inulin and sucrose as substrates. Hence, I/S ratio is used to distinguish the catalytic activity of the enzyme and to determine its inulinase or invertase activity. I/S ratio greater than $10^{-2}$ determines inulinase activity, while ratio lower than $10^{-4}$ demonstrates invertase activity (25). In the present study, maximum inulinase was produced at I/S ratio of 3.38 . High I/S ratio confirmed the inulolytic nature of the produced 
enzyme. Moreover, I/S ratio obtained from all 15 experimental combinations was also very high, which confirms the conformational specificity of the enzyme active site for inulin only. Other fungal sources such as Aspergillus parasiticus, P. spinulosum and Trichoderma viride have also been reported to show high I/S ratio, i.e. 1.61, 1.79 and 2.6 , respectively (26), which however, is lower than the ratio obtained in the present work.

The interactive effect of moisture content and $\mathrm{pH}$ on inulinase production and I/S ratio is shown in Figs. $1 \mathrm{~b}$ and $2 \mathrm{~b}$. At $\mathrm{pH}=7.0$ and moisture content of $90 \%$, maximum inulinase production was obtained, while at very low and high $\mathrm{pH}$ and moisture content, a reduction in inulinase production was observed. Our results are in accordance with the fact that most of the fungi show optimal growth in slightly acidic or neutral environment. Moreover, extremely high or low moisture content do not induce proper fungal growth, which further pronouncedly reduces metabolite production. Interaction of fermentation time with moisture content and $\mathrm{pH}$ also showed a significant effect on inulinase production and I/S ratio (Figs. $1 \mathrm{a}, 1 \mathrm{c}, 2 \mathrm{a}$ and $2 \mathrm{c}$ ). Fermentation time of 4 days, moisture content of $90 \%$ and $\mathrm{pH}=7.0$ were observed to be optimal for inulinase production. However, fermentation time beyond 4 days decreased the inulinase yield from 322.10 to $272.70 \mathrm{IU}$ per $\mathrm{g}$ of dry substrate. This may be attributed to protease secretion into the medium, diminution of important medium constituents or accumulation of secondary metabolites. Decrease in inulinase production also showed a significant effect on I/S ratio.

\section{Validation of experimental model}

The predicted values of inulinase production and I/S ratio obtained from the designed model at optimized conditions (moisture content $90 \%$, incubation time 4 days and $\mathrm{pH}=7.0$ ) were $321.61 \mathrm{IU}$ per g of dry substrate and 3.33, respectively. To testify the validation of the model for predicting inulinase production and I/S ratio, experimental trial was conducted in triplicates using optimized conditions. The performed experiments yielded $322.10 \mathrm{IU}$ per $\mathrm{g}$ of dry substrate and 3.38 for inulinase production and the corresponding I/S ratio, respectively. Comparison between these values indicates good agreement between experimental and predicted data, which verifies the validity of current model and existence of an optimal point.

\section{CONCLUSIONS}

Carrot pomace has been found to be a suitable substrate for the production of inulinase by Penicillium oxalicum BGPUP-4 in solid-state ferementation. Statistical optimization has proved to be a successful approach for the optimization of inulinase production by P. oxalicum BGPUP-4. A substantial 2.5-fold increase in inulinase production in comparison with the control (optimized using one-factor-at-a-time method, data not shown) was observed after response surface optimization.

\section{ACKNOWLEDGEMENT}

Authors are thankful to Head, Department of Biotechnology, Punjabi University, Patiala, India, for providing the necessary laboratory facilities to execute the present work.

\section{REFERENCES}

1. Singh RS, Dhaliwal R, Puri M. Development of a stable continuous flow immobilized enzyme reactor for the hydrolysis of inulin. J Ind Microbiol Biotechnol. 2008;35:777-82. https://doi.org/10.1007/s10295-008-0348-3

2. Singh RS, Sooch BS, Puri M. Optimization of medium and process parameters for the production of inulinase from a newly isolated Kluyveromyces marxianus YS-1. Bioresour Technol. 2007;98:2518-25.

https://doi.org/10.1016/j.biortech.2006.09.011

3. Singh RS, Dhaliwal R, Puri M. Partial purification and characterization of exoinulinase from Kluyveromyces marxianus YS-1 for preparation of high-fructose syrup. J Microbiol Biotechnol. 2007;17:733-8.

4. Singh RS, Singh RP. Production of fructooligosaccharides from inulin by endoinulinases and their prebiotic potential. Food Technol Biotechnol. 2010;48:435-50.

5. Singh RS, Singh RP, Kennedy JF. Recent insights in enzymatic synthesis of fructooligosaccharides from inulin. Int J Biol Macromol. 2016;85:565-72. https://doi.org/10.1016/j.jibiomac.2016.01.026

6. Singh RS, Chauhan K. Production, purification, characterization and applications of fungal inulinases. Curr Biotechnol. 2016;5.

https://doi.org/10.2174/2211550105666160512142330

7. Singh RS, Chauhan K, Kennedy JF. A panorama of bacterial inulinases: Production, purification, characterization and industrial applications. Int J Biol Macromol. 2017;96:312-22. https://doi.org/10.1016/j.ijbiomac.2016.12.004

8. Singh RS, Singh RP. Inulinases. In: Pandey A, Negi S, Soccol $\mathrm{CR}$, editors. Current developments in biotechnology and bioengineering. Production, isolation and purification of industrial products. Amsterdam, The Netherlands: Elsevier Inc; 2017. pp. 423-46.

https://doi.org/10.1016/B978-0-444-63662-1.00018-X

9. Sharma KD, Karki S, Thakur NS, Attri S. Chemical composition, functional properties and processing of carrot - a review. J Food Sci Technol. 2012;49:22-32. https://doi.org/10.1007/s13197-011-0310-7

10. Demiray E, Karatay SE, Dönmez S, Dönmez G. The usage of carrot pomace for bioethanol production. J Chil Chem Soc. 2016;61:2996-8.

https://doi.org/10.4067/S0717-97072016000200029

11. Singh RS, Chauhan K. Inulinase production from a new inulinase producer, Penicillium oxalicum BGPUP-4. Biocatal Agric Biotechnol. 2017;9:1-10. https://doi.org/10.1016/j.bcab.2016.10.012 
12. Miller GL. Use of dinitrosalicyclic acid reagent for determination of reducing sugar. Anal Chem. 1959;31:426-8.

https://doi.org/10.1021/ac60147a030

13. Mazutti MA, Zabot G, Boni G, Skovronski A, de Oliveira D, Di Luccio $M$, et al. Optimization of inlinase production by solid-state fermentation in a packed-bed reactor. J Chem Technol Biotechnol. 2010;85:105-14. https://doi.org/10.1002/jctb.2273

14. Singh RS, Lotey S. Enhanced exoinulinase production from Kluyveromyces marxianus YS-1 using response surface methodology. Braz Arch Biol Technol. 2010;53:1005-13. https://doi.org/10.1590/S1516-89132010000500002

15. Singh RS, Singh H, Saini GK. Response surface optimization of the critical medium components for pullulan production by Aureobasidium pullulans FB-1. Appl Biochem Biotechnol. 2009;152:42-53. https://doi.org/10.1007/s12010-008-8180-9

16. Singh RS, Singh RP. Response surface optimization of endoinulinase production from a cost effective substrate by Bacillus safensis AS-08 for hydrolysis of inulin. Biocatal Agric Biotechnol. 2014;3:365-72. https://doi.org/10.1016/j.bcab.2014.05.002

17. Singh RS, Singh RP, Kennedy JF. Endoinulinase production by a new endoinulinase producer Aspergillus tritici BGPUP6 using a low cost substrate. Int J Biol Macromol. 2016;92:1113-22.

https://doi.org/10.1016/j.ijbiomac.2016.08.026

18. Guo N, Gong F, Chi Z, Sheng J, Li J. Enhanced inulinase production in solid state fermentation by the mutant of marine yeast Pichia guilliermondii using surface response methodology and inulin hydrolysis. J Ind Microbiol Biotechnol. 2009;36:499-507. https://doi.org/10.1007/s10295-008-0519-2

19. Nuñez-Gaona O, Saucedo-Castañeda G, Alatorre-Rosas R, Loera O. Effect of moisture content and inoculum on the growth and conidia production by Beauveria bassiana on wheat bran. Braz Arch Biol Technol. 2010;53:771-7.

https://doi.org/10.1590/S1516-89132010000400004

20. Dinaravand M, Rezaee M, Foroughi M. Optimizing culture conditions for production of intracellular and extracellular inulinase and invertase from Aspergillus niger ATCC 20611 by response surface methodology (RSM). Braz J Microbiol. 2017;48:427-41.

https://doi.org/10.1016/j.bjm.2016.10.026

21. Makino Y, Treichel H, Mazutti MA, Maugeri F, Rodrigues MI. Inulinase bio-production using agroindustrial residues: Screening of microorganisms and process parameters optimization. J Chem Technol Biotechnol. 2009;84:1056-62. https://doi.org/10.1002/jctb.2134

22. Raimbault M, Alazard D. Culture method to study fungal growth in solid fermentation. Eur J Appl Microbiol Biotechnol. 1980;9:199-209. https://doi.org/10.1007/BF00504486

23. Singh RS, Singh RP, Yadav M. Molecular and biochemical characterization of a new endoinulinase producing bacterial strain of Bacillus safensis AS-08. Biologia. 2013;68:102833.

https://doi.org/10.2478/s11756-013-0259-2

24. Danial EN, Al-Bishri WKW. New isolate for enhancement production of microbial inulinase. Biosci J. 2015;31:1550-60. https://doi.org/10.14393/BJ-v31n5a2015-28265

25. Ettalibi M, Baratti JC. Purification, properties and comparison of invertase, exoinulinases and endoinulinases of Aspergillus ficuum. Appl Microbiol Biotechnol. 1987;26:13-20. https://doi.org/10.1007/BF00282143

26. Ertan F, Ekinci F, Aktac T. Production of inulinases from Penicillium spinulosum, Aspergillus parasiticus NRRL2999 and Trichoderma viride. Pak J Biol Sci. 2003;6:1332-5. https://doi.org/10.3923/pjbs.2003.1332.1335 